\title{
Variable Outcome of Acute Viral Hepatitis in Diabetic and Nondiabetic Patients in Bangladesh
}

\author{
Harun-or-Rashid ${ }^{1}$, Mahbubur R Khan, ${ }^{2}$ Tasnova Rashid, ${ }^{3}$ Humaira Rashid, ${ }^{4}$ Mamun-Al-Mahtab ${ }^{5}$
}

\begin{abstract}
Diabetes mellitus (DM) are common in Bangladesh, and this country is also well-known for frequent outbreaks of acute viral hepatitis (AVH). The study presented here was designed for the clinical courses of acute hepatitis with and without DM. A total of 300 patients with AVH were enrolled into two groups; group A; patients of AVH with DM $(N=140)$ and group $B$; patients with AVH without DM $(N=160)$. There was no significant difference regarding age, sex, and levels of alanine aminotransferase (ALT) between the two groups. The main cause of AVH was hepatitis $E$ virus (HEV) in 100 and 112 patients of groups $A$ and $B$, respectively. Jaundice persisted for more than 6 months in 68 of 140 (49\%) patients of group A, whereas, this was found in only 11 of 160 patients of group B. Forty-two patients of group A showed evidence of esophageal varices; however, the endoscopic assessment did not reveal any abnormality in patients with group $B$. Moderate to several hepatic fibrosis was seen in 19 of 140 patients with group A, however, these were not detected in any patient of group B (patient with AVH without DM). Even more important is the fact that four patients of group A died of liver failure, whereas there was no mortality in any patient of group B. The study presented here indicates that all patients with DM with superimposed AVH should be carefully followed up with the possibility of development of severe liver diseases and even mortality.

Keywords: Acute viral hepatitis, Diabetes mellitus, Hepatitis E virus.

Euroasian Journal of Hepato-Gastroenterology (2019): 10.5005/jp-journals-10018-1290
\end{abstract}

\section{INTRODUCTION}

A cute viral hepatitis (AVH) is usually a self-limiting condition that has a typical course of prodromal symptoms followed by an icteric phase. In some cases, the course may be critical or complicated by the development of cholestatic phase or acute liver failure or may turn to chronic liver disease. The complications depend on several factors such as type of the virus, age of infection, immune status of the host, and superinfection with immune suppressive viruses. ${ }^{1-4} \mathrm{AVH}$ is still common morbidity of Bangladesh. AVH in sporadic, endemic and epidemic forms are reported from this country each year. ${ }^{1}$

Diabetes mellitus (DM), a metabolic disorder, has been demonstrated as a risk factor for both chronic liver disease and hepatocellular carcinoma (HCC) ${ }^{5,6}$ Bangladesh, a country of 160 million people, harbors quite a high percentage of DM patients, although the proper epidemiological studies have not been accomplished in this country. Circumstantial evidence indicates that there may be more than 20 million people with DM in Bangladesh. ${ }^{7}$

There has been a consensus among physicians and even hepatologists of Bangladesh that AVH is a self-limiting pathological condition and little attention is provided for follow-up of these patients. The study was planned to assess if the clinical features of patents differ when AVH is superimposed in DM patients. ${ }^{8,9}$

\section{Materials and methods}

This is a descriptive cross-sectional study. The study is prospective in nature. The patients attended the two institutions of Rajshahi, Bangladesh (Rajshahi Medical College Hospital Inpatients and Outpatients Department, and Rajshahi Diabetic Association Hospital, Rajshahi, Bangladesh) for more than 3 years (May 2010 to July 2013). All patients were selected based on inclusion and exclusion criteria. Adults of both sexes were enrolled in this study. All patients have been suffering from DM and exhibited clinical and biochemical features of AVH. Patients
${ }^{1,2}$ Department of Hepatology, Rajshahi Medical College Hospital, Rajshahi, Bangladesh

${ }^{3}$ Department of Medicine, Medical College for Women and Hospital, Dhaka, Bangladesh

${ }^{4}$ Department of Pharmacy, Brac University, Dhaka, Bangladesh

${ }^{5}$ Department of Hepatology, Bangabandhu Sheikh Mujib Medical University, Dhaka, Bangladesh

Corresponding Author: Harun-or-Rashid, Department of Hepatology, Rajshahi Medical College Hospital, Rajshahi, Bangladesh, Phone: 880171-119 04778, e-mail:drharun_bd@yahoo.com

How to cite this article: Harun-or-Rashid, Khan MR, et al. Variable Outcome of Acute Viral Hepatitis in Diabetic and Nondiabetic Patients in Bangladesh. Euroasian J Hepatogastroenterol 2019;9(1): 20-22.

Source of support: Nil

Conflict of interest: None

with the intake of drugs known to cause acute hepatitis, history of alcohol ingestion $>40 \mathrm{mg} /$ day, malaria hepatitis, enteric hepatitis, leptospirosis, septicemia, HIV coinfection, associated comorbidities, cardiovascular disease and diabetic nephropathy, pregnant female and patients with known liver diseases were excluded from the study.

All patients were followed up for 12 months or until being fully cured. To have more insights about the development of complications, upper gastrointestinal endoscopy was performed in all patients. Also, abdominal ultrasonography was done in all patients. Fibroscan was also done to develop insights about the levels of hepatic fibrosis.

\section{Ethical Issue}

Eligibility of each case has been assessed and identified, and every patient and or responsible family member was asked for informed

(0) The Author(s). 2019 Open Access This article is distributed under the terms of the Creative Commons Attribution 4.0 International License (https://creativecommons. org/licenses/by-nc/4.0/), which permits unrestricted use, distribution, and non-commercial reproduction in any medium, provided you give appropriate credit to the original author(s) and the source, provide a link to the Creative Commons license, and indicate if changes were made. The Creative Commons Public Domain Dedication waiver (http://creativecommons.org/publicdomain/zero/1.0/) applies to the data made available in this article, unless otherwise stated. 
consent. They have been informed about the procedure and study goal. The eligible patient or family member has been informed that there is no extra cost to the patients for the investigations. They have also been informed that they are free to refuse to participate or to withdraw at any time without compromising their medical care. Patients name and age have been recorded initially to link their clinical and laboratory data. At enrollment, they have been assigned a unique study identification number (ID), which used to level all study materials. Completed data collection forms and information linking patient personal identifiers to questionnaires have been kept by the principal investigator regularly to which no one has got any access. The procedures in the protocol present no risk to participants.

\section{Statistical Analysis}

Data have been analyzed with the help of the statistical package for social sciences (SPSS) software program and expressed as mean \pm SD. $p$ value $<0.05$ have been considered significant.

\section{Results}

The mean age of the patients of group $A$ ( $52.2 \pm 8.0$ years), and group $B(51.5 \pm 9.1$ years) was comparable. Also, a significant difference in sex distribution was not detected between groups, and there was male predominance in both groups. The levels of ALT were also comparable between groups with considerable diversity among patients (group A: $569 \pm 361 \mathrm{IU} / \mathrm{L}$; range 77-1500 IU/L; group B: 605 $\pm 323 \mathrm{lU} / \mathrm{L}$, range: $99-1598 \mathrm{IU} / \mathrm{L})$. The levels of bilirubin were higher in patients of group A (5.17-19.5 gm/dL) compared with those of group B: $1.32-18.0 \mathrm{mg} / \mathrm{dL}$ ).

The etiology of AVH were mostly by HEV in both groups (group A: 100 of 140 patients (71\%); group B: 112 of 160 (70\%). HBV was the next important etiological agent of $A V H$ in both groups. HAV induced $A V H$ in three patients of group $B$. The etiological agent of AVH remained unexplored in some patients.

Dyslipidemia was found in 25 of 140 patients of group $A$ (18\%) and 12 of 160 patients of group B (7.5\%) indicating significant higher abnormal lipid profile in patients of group $A$.

Jaundice persisted for more than 6 months in 68 of 140 patients of group A. Important findings were elucidated by further checking of their clinical and physical status. Out of 68 patients, 60 patients developed ascites. The 68 patients who showed jaundice for more than 6 months were further explored for evidence of portal hypertension by endoscopic examination (Table 1). Esophageal varices of small and medium size were detected in 33 and 9 patients, respectively. To have further insights about the extents of liver fibrosis of these patients, fibroscan was accomplished in these patients. Mild and moderate fibrosis was

Table 1: Endoscopic evaluation of patients of group $B$ with jaundice for more than 6 months $(N=68)$

\begin{tabular}{lll}
\hline Endoscopy of UGI & No of patients & \% of the patients \\
\hline $\begin{array}{l}\text { Esophageal varices (small } \\
\text { sized) with gastropathy }\end{array}$ & 33 & 48.5 \\
$\begin{array}{l}\text { Esophageal varices } \\
\text { (medium-sized with }\end{array}$ & 9 & 13.2 \\
$\begin{array}{l}\text { gastropathy) } \\
\text { Gastropathy without } \\
\text { esophageal varices }\end{array}$ & 26 & 38.2 \\
\hline Total & 68 & 100 \\
\hline
\end{tabular}

Table 2: Elastography of liver of the patients of group B with jaundice for more than 6 months $(\mathrm{N}=68)$

\begin{tabular}{lll}
\hline Elastography findings & No of patients & Percentage (\%) \\
\hline Mild fibrosis (8-11 Kpa) & 49 & 72.05 \\
Moderate (12-21 Kpa) & 14 & 20.58 \\
Severe (>22 Kpa) & 05 & 7.35 \\
\hline
\end{tabular}

found in 49 and 14 patients, respectively, whereas, severe fibrosis of more than $22 \mathrm{Kpa}$ was seen in five patients (Table 2). Finally, four patients of group $B$ died due to liver failure, whereas there was no mortality of patients in group $A$.

The findings of abdominal ultrasonography indicated that there was no evidence of chronic liver diseases in patients of group B. Of 160 patients, 149 (93.12\%) resolved AVH and serum bilirubin within 1 month and only in 11 of 160 patients. Jaundice persisted for 1-3 months.

\section{Discussion}

Acute viral hepatitis (AVH) is usually associated with complete spontaneous clinical, biochemical and virological recovery within 4-6 weeks of onset that attributed its status as a self-limiting disease. However, with the advancement of time and proper follow-up of AVH patients, it appears that AVH is not a complete benign entity. Studies have revealed that $1-5 \%$ of patients with $A V H$ develop complications like an acute liver failure (ALF), subacute hepatic failure or prolonged icteric course. The known factors of such complicated natural course include the specific viral etiology, ${ }^{10}$ host factors such as immunological status, age of infection and presence of preexisting chronic liver disease. ${ }^{11}$

However, little has been explored about lifestyle-related pathologies in the outcome of $\mathrm{AVH}$. The study presented here has shown that $\mathrm{AVH}$ without DM runs a benign course and all patients recovered within 4 weeks after attending physicians. On the other hand, when patients with $\mathrm{AVH}$ also had DM, a major bulk of patients had an extensively prolonged course of jaundice (more than 6 months). Considerable numbers of patients also developed evidence of portal hypertension and chronic liver damages. Also, complications like ascites were seen in some of these patients. Hepatic fibrosis of different grades was documented in these 68 patients. Finally, four patients with DM plus AVH died due to liver failure.

Taken together, it appears that preexisting DM is an important factor regulating the natural course of $\mathrm{AVH}$. However, all data of this study requires serious consideration as prolonged morbidity and even mortality was found in patients with AVH superimposed DM. However, the underlying mechanisms could not be explored in this clinical study of open-level nature. Future studies should explore if the patients with DM also had other comorbidities or not. A study in a bigger cohort and long term follow-up may unmask some important facts about the management of AVH in DM.

In conclusion, $\mathrm{AVH}$ is not a benign and self-limiting disease as this has been described before for all types of patients. Special attention should be taken to patients with DM. Prolonged follow-up of these patients is also mandatory.

\section{References}

1. Harun-Or-Rashid M, Akbar SM, et al. Epidemiological and molecular analyses of a non-seasonal outbreak of acute icteric hepatitis $E$ in Bangladesh, J Med Virol 2013;85:1369-1376 
2. Zhang S, Wang J, et al. Clinical characteristics and risk factors of sporadic hepatitis E in central China. Virol J 2011;8:152-152.

3. Al-Mahtab M, Rahman S, et al. HEV infection as an aetiologic factor for acute hepatitis: Experience from a tertiary hospital in Bangladesh. J Health Popul Nutr 2009;27:14-19.

4. Manka $P$, Bechmann LP, et al. Hepatitis E virus infection as a possible cause of acute liver failure in Europe. Clin Gastroenterol Hepatol 2015;13(10):1836-42.e2.

5. Stepanova $\mathrm{M}, \mathrm{Clement} \mathrm{S}$, et al. Patients with diabetes and chronic liver disease are at increased risk for overall mortality: A Population Study From the United States. Clin Diabetes 2017;35(2):79-83.

6. Chen J, Han Y, et al. Effect of type 2 diabetes mellitus on the risk for hepatocellular carcinoma in chronic liver diseases: a meta-analysis of cohort studies. Eur J Cancer Prev 2015;24(2):89-99.
7. Wild S, Roglic G, et al. Global prevalence of diabetes: estimates for the year 2000 and projections for 2030. Diabetes Care 2004;27(5):10471053.

8. Monga R, Garg S, et al. Superimposed acute hepatitis E infection in patients with chronic liver disease. Indian J Gastroenterol 2004;23:50 52

9. Ramachandran J, Eapen CE, et al. Hepatitis E superinfection produces severe decompensation in patients with chronic liver disease. J Gastroenterol Hepatol 2004;19(2):134-138.

10. O'Grady JG, Alexander GJM, et al. Early indicators of prognosis in fulminant hepatic failure. Gastroenterology. 1989;97:439-445.

11. Kumar A, Aggarwal R, et al. Hepatitis E virus is responsible for decompensation of chronic liver disease in an endemic region. Indian J Gastroenterol 2004;23:59-62. 